Research Paper

\title{
Choice of Treatment for Stage IA Non-small Cell Lung Cancer Patients Ineligible for Surgery: Ablation or Stereotactic Body Radiotherapy?
}

\author{
Long Liang1,2\#, Guoshu Li1", Shuanshuan Xie ${ }^{1 \#, ~ G u i f e n g ~ S u n ², ~ M e n g m e i ~ Z h a n g ~}{ }^{2}$, Fenyong Sun², Aimei \\ Peng $1^{\bowtie}$ \\ 1. Department of Respiratory Medicine, Shanghai Tenth People's Hospital, Tongji University, Shanghai 200072, China \\ 2. Department of Clinical Laboratory, Shanghai Tenth People's Hospital, Tongji University, Shanghai 200072, China \\ \# These authors have contributed equally to this work \\ $\square$ Corresponding author: Aimei Peng, Email: wang-chang-hui@hotmail.com, Fax number: 86-021-66301685, Telephone: 86-021-66301685 \\ (c) The author(s). This is an open access article distributed under the terms of the Creative Commons Attribution License (https://creativecommons.org/licenses/by/4.0/). \\ See http://ivyspring.com/terms for full terms and conditions.
}

Received: 2019.08.19; Accepted: 2019.12.07; Published: 2020.01.14

\begin{abstract}
Purpose: To compare the survival outcomes of ablation and stereotactic body radiotherapy (SBRT) in inoperable patients with stage IA non-small cell lung cancer (NSCLC).

Patients and Methods: Using the Surveillance, Epidemiology, and End Results (SEER) database, we identified 6,395 patients with stage IA NSCLC who had complete clinical information from 2004 to 2015. Kaplan-Meier analysis was performed to determine the propensity score based on the clinical characteristics of patients with stage IA NSCLC. Overall survival (OS) was compared between patients with stage IA NSCLC who were treated with ablation and SBRT after adjusting, stratifying, or matching.

Results: Kaplan-Meier analysis demonstrated no significant difference in survival curves (log-rank, $p>0.05$ ) between the ablation and SBRT groups. Compared with the SBRT group, the hazard ratio $(\mathrm{HR})(95 \%$ confidence interval $[\mathrm{Cl}])$ of OS was $0.930(0.817-1.058, p=0.269)$ in the ablation group on univariate analysis. On multivariate analysis, similar effects on OS (HR: $0.974,95 \% \mathrm{Cl}: 0.858-$ $1.105, p=0.680$ ) were seen in patients with stage IA NSCLC in both the groups.

Conclusions: This study suggests that survival does not differ significantly between patients with stage IA NSCLC treated with ablation and SBRT. These results will be helpful for patients with stage IA NSCLC who are ineligible for surgery.
\end{abstract}

Key words: Ablation, SBRT, non-small cell lung cancer, SEER, overall survival

\section{Introduction}

According to the American Cancer Center, there were about 234,030 newly diagnosed lung cancer patients in 2018, of which more than $80 \%$ had non-small cell lung cancer (NSCLC) ${ }^{1,2}$. Early-stage lung cancer patients account for $16 \%$ of newly diagnosed cases, diagnosed according to the criteria of the American Joint Commission for Cancer stage I or II disease ${ }^{3}$. Currently, surgery is the gold standard for treatment of early-stage NSCLC ${ }^{4}$. However, $>20 \%$ of patients with early-stage NSCLC are ineligible for surgery because of various factors such as old age, severe impairment of lung function, or other comorbidities $^{5}$. Therefore, viable alternatives, including ablation and SBRT, have been emerging to achieve reliable local control in such patients ${ }^{6,7}$. Three-year local control rates of up to $90 \%$ were observed on application of SBRT for early-stage lung cancer6,8. Ablation, including laser ablation, cryotherapy, electrocautery, and fulguration, is an image-guided technique9. Good local-regional control 
has been reported with ablation, compared to that with SBRT, for patients with inoperable NSCLC ${ }^{10,11}$. To date, no large population-based studies have been performed using a cancer database to compare clinical outcomes between ablation and SBRT cohorts. In addition, there have been no randomized studies or prospective trials for assessing the effectiveness of the two treatments. The purpose of this study was to compare survival rates between patients with stage IA NSCLC treated with ablation and SBRT using the Surveillance, Epidemiology, and End Results (SEER) database.

\section{Patients and Methods}

\section{Data Source}

The data used in this study were extracted from the SEER database. The SEER database is sponsored by the US National Cancer Institute and collects registry information, including that of patient survival, pathological type, disease stage, and treatment. The SEER database was established in 1973 and contains data of approximately $10 \%$ of the US population.

\section{Study Population}

We limited the cohort to patients diagnosed with stage IA NSCLC (tumor size $\leq 3 \mathrm{~cm}$ ) between 2004 and 2015. All included patients were inoperable and underwent SBRT or ablation (including laser ablation, cryotherapy, electrocautery, and fulguration). Complete patient information was available in the SEER database.

\section{Covariates}

Baseline characteristics were based on 14 covariates, including age, sex, tumor size, race, differentiation grade, tumor location, histologic type, laterality, insurance status, marital status, year of diagnosis, geographic region, education level, and median household income.

\section{Clinicopathological Data}

According to histologic type, NSCLC cases were classified as follows: (1) squamous cell carcinoma (SQCC) (histologic codes 8052, 8070-8075, 8083, 8084, 8123); (2) adenocarcinoma (AD) (histologic codes $8244,8245,8250-8255,8260,8290,8310,8323,8333$, $8480,8481,8490,8507,8550,8570,8571,8574$, and 8576); and (3) large cell carcinoma (histologic codes 8012-8014). According to the SEER criteria, all 6,395 patients with stage IA NSCLC were classified as having undergone SBRT (using regional treatment modality-specific codes) or ablation, defined as laser ablation/cryotherapy (SEER surgical code 12) and electrocautery/fulguration (includes use of hot forceps for tumor destruction; SEER surgical code 13).

\section{Statistical Analyses}

All data were analyzed using IBM SPSS, version 20.0 (IBM Corp, Armonk, NY, USA). Kaplan-Meier analysis was performed to compare survival curves between the ablation and SBRT groups. Propensity score methods were used to control for potential differences in the baseline characteristics of the included patients. Cox regression analysis was performed to assess the balance in baseline covariates between the two groups after adjusting for the estimated propensity scores.

\section{Results}

\section{Baseline Cohort Characteristics}

A total of 6395 patients with stage IA NSCLC who were treated with SBRT or ablation as primary treatment from 2004 to 2015 were identified. The number of patients who received SBRT and ablation were $6004(93.89 \%)$ and 391(6.11\%), respectively. Table 1 shows the baseline characteristics of all patients, identified through the SEER database. Kaplan-Meier analyses demonstrated significant differences in overall survival (OS) between the two groups according to sex $(p<0.001)$, age $(\mathrm{p}<0.001)$, tumor size $(p<0.001)$, histologic type $(p<0.001)$, differentiation grade $(\mathrm{p}<0.001)$, insurance status $(p<0.001)$, year of diagnosis $(p<0.001)$, and geographic region $(p=0.002)$. However, no significant differences in OS were observed with respect to race $(p=0.080)$, tumor location $(p=0.062)$, laterality $(p=0.734)$, marital status $(p=0.340)$, education level $(p=0.425)$, and median household income $(p=0.531)$ (Table 1$)$.

\section{Comparison of Disease-specific Mortality and Median Survival between the SBRT and Ablation Groups}

The overall lung cancer-specific mortality rate in patients with stage IA NSCLC was $29.5 \%$ (1886/6395). The mortality rates were $29.0 \%(1739 / 6004)$ and $37.6 \%$ $(147 / 391)$ in the SBRT and ablation groups, respectively. The overall median survival of patients with stage IA NSCLC was 20 months. The median survival in the SBRT and ablation groups were 20 and 31 months, respectively (Table 2). Compared to the SBRT group, the crude hazard ratio (HR) $(95 \%$ confidence interval [CI]) was 0.931 (0.821-1.055, $p=0.260$ ) for patients with stage IA NSCLC in the ablation group. In patients with stage IA SQCC, the HR (95\% CI) was $0.877(0.684-1.124, p=0.299)$ in the ablation group, compared to the SBRT group. In patients with stage IA AD, the HR $(95 \% \mathrm{CI})$ in the ablation group was 0.919 (0.768-1.099, $p=0.353)$, compared to the SBRT group (Table 3). 
Table 1. Baseline Characteristics of Patients with Stage IA NSCLC Treated with SBRT and Ablation in the SEER Program, 2004-2015

\begin{tabular}{|c|c|c|c|c|c|c|c|}
\hline \multirow[b]{2}{*}{ Characteristics } & \multicolumn{2}{|l|}{ NSCLC } & \multicolumn{2}{|l|}{ SBRT } & \multicolumn{2}{|l|}{ Ablation } & \multirow[b]{2}{*}{$p$} \\
\hline & Number & $\%$ & Number & $\%$ & Number & $\%$ & \\
\hline Age, year & & & & & & & $<0.001$ \\
\hline$<45$ & 6 & 0.1 & 6 & 0.1 & 0 & 0 & \\
\hline$\geq 45,<55$ & 119 & 1.9 & 110 & 1.8 & 9 & 2.3 & \\
\hline$\geq 55,<65$ & 785 & 12.3 & 730 & 12.2 & 55 & 14.1 & \\
\hline$\geq 65,<75$ & 2090 & 32.7 & 1964 & 32.7 & 126 & 32.2 & \\
\hline$\geq 75$ & 3395 & 53.0 & 3194 & 53.2 & 201 & 51.4 & $<0.001$ \\
\hline \multicolumn{8}{|l|}{ Sex } \\
\hline Female & 3607 & 56.4 & 3387 & 56.4 & 220 & 56.3 & \\
\hline Male & 2788 & 43.6 & 2617 & 43.6 & 171 & 43.7 & 0.080 \\
\hline \multicolumn{8}{|l|}{ Race } \\
\hline White & 5331 & 83.4 & 5156 & 85.9 & 175 & 44.7 & \\
\hline Black & 776 & 12.1 & 574 & 9.6 & 202 & 51.7 & \\
\hline Others & 279 & 4.4 & 265 & 4.4 & 14 & 3.6 & \\
\hline Unknown & 9 & 0.1 & 9 & 0.1 & 0 & 0 & $<0.001$ \\
\hline \multicolumn{8}{|l|}{ Tumor size, $\mathrm{cm}$} \\
\hline$\leq 1$ & 325 & 5.1 & 272 & 4.5 & 53 & 13.6 & \\
\hline$>1, \leq 2$ & 3135 & 49.0 & 2926 & 48.7 & 209 & 53.5 & \\
\hline$>2, \leq 3$ & 2917 & 45.6 & 2795 & 46.6 & 122 & 31.2 & \\
\hline Unknown & 18 & 0.3 & 11 & 0.2 & 7 & 1.7 & 0.062 \\
\hline \multicolumn{8}{|l|}{ Tumor location } \\
\hline Upper lobe & 3945 & 61.7 & 3715 & 61.9 & 230 & 58.8 & \\
\hline Middle lobe & 293 & 4.6 & 270 & 4.5 & 23 & 5.9 & \\
\hline Lower lobe & 2023 & 31.6 & 1892 & 31.5 & 131 & 33.5 & \\
\hline NOS & 101 & 1.6 & 96 & 1.6 & 5 & 1.3 & \\
\hline Overlapping lesion & 11 & 0.2 & 11 & 0.2 & 0 & 0 & \\
\hline Main bronchus & 22 & 0.3 & 20 & 0.3 & 2 & 0.5 & $<0.001$ \\
\hline \multicolumn{8}{|l|}{ Differentiated grade } \\
\hline Grade I & 548 & 8.6 & 503 & 8.4 & 45 & 11.5 & \\
\hline Grade II & 1054 & 16.5 & 994 & 16.6 & 60 & 15.3 & \\
\hline Grade III & 1283 & 20.1 & 1212 & 20.2 & 71 & 18.2 & \\
\hline Grade IV & 35 & 0.5 & 33 & 0.5 & 2 & 0.5 & \\
\hline Unknown & 3475 & 54.3 & 3262 & 54.3 & 213 & 54.5 & $<0.001$ \\
\hline Histologic type & & & & & & & \\
\hline Squamous cell carcinoma & 2112 & 33.0 & 2017 & 33.6 & 95 & 24.3 & \\
\hline Adenocarcinoma & 3113 & 48.7 & 2897 & 48.3 & 216 & 55.2 & \\
\hline Large cell carcinoma & 71 & 1.1 & 68 & 1.1 & 3 & 0.8 & \\
\hline Other & 1099 & 17.2 & 1022 & 17.0 & 77 & 19.7 & 0.734 \\
\hline Laterality & & & & & & & \\
\hline Right-origin of primary & 3647 & 57.0 & 3418 & 56.9 & 229 & 58.6 & \\
\hline Left-origin of primary & 2748 & 43.0 & 2586 & 43.1 & 162 & 41.4 & $<0.001$ \\
\hline Insurance status & & & & & & & \\
\hline Medicaid & 650 & 10.2 & 627 & 10.4 & 23 & 5.9 & \\
\hline Uninsured & 32 & 0.5 & 30 & 0.5 & 2 & 0.5 & \\
\hline Unknown & 813 & 12.7 & 705 & 11.7 & 108 & 27.6 & \\
\hline Insured & 4900 & 76.6 & 4642 & 77.4 & 258 & 66.0 & 0.340 \\
\hline Marital status & & & & & & & \\
\hline Married & 2753 & 43.0 & 2582 & 43.0 & 171 & 43.7 & \\
\hline Single & 695 & 10.9 & 650 & 10.9 & 45 & 11.5 & \\
\hline Divorced & 841 & 13.2 & 786 & 13.1 & 55 & 14.1 & \\
\hline Widowed & 1817 & 28.4 & 1707 & 28.4 & 110 & 28.1 & \\
\hline Unknown & 280 & 4.4 & 270 & 4.5 & 10 & 2.6 & \\
\hline Unmarried or Domestic Partner & 9 & 0.1 & 9 & 0.1 & 0 & 0 & $<0.001$ \\
\hline Year of diagnosis & & & & & & & \\
\hline $2004-2007$ & 1013 & 15.8 & 866 & 14.4 & 147 & 37.6 & \\
\hline 2008-2011 & 1969 & 30.8 & 1814 & 30.2 & 155 & 39.6 & \\
\hline 2012-2015 & 3413 & 53.4 & 3324 & 55.4 & 89 & 22.8 & 0.002 \\
\hline Geographic region & & & & & & & \\
\hline East & 2799 & 43.8 & 2673 & 44.6 & 126 & 32.2 & \\
\hline Northwest & 11 & 0.2 & 11 & 0.2 & 0 & 0 & \\
\hline West & 2532 & 39.6 & 2301 & 38.3 & 231 & 59.1 & \\
\hline North & 882 & 13.7 & 855 & 14.2 & 27 & 6.9 & \\
\hline Southwest & 171 & 2.7 & 164 & 2.7 & 7 & 1.8 & 0.425 \\
\hline High school education & & & & & & & \\
\hline$\geqslant 21$ & 841 & 13.2 & 758 & 12.6 & 83 & 21.2 & \\
\hline $13-20$ & 1933 & 30.2 & 1810 & 30.1 & 123 & 31.5 & \\
\hline $7-12$ & 3103 & 48.5 & 2952 & 49.2 & 151 & 38.6 & \\
\hline$<7$ & 518 & 8.1 & 484 & 8.1 & 34 & 8.7 & \\
\hline Median household income (dollar, in tons) & & & & & & & 0.531 \\
\hline$<38000$ & 361 & 5.6 & 356 & 5.9 & 5 & 1.3 & \\
\hline
\end{tabular}




\begin{tabular}{|c|c|c|c|c|c|c|c|}
\hline \multirow[b]{2}{*}{ Characteristics } & \multicolumn{2}{|l|}{ NSCLC } & \multicolumn{2}{|l|}{ SBRT } & \multicolumn{2}{|l|}{ Ablation } & \multirow[b]{2}{*}{$p$} \\
\hline & Number & $\%$ & Number & $\%$ & Number & $\%$ & \\
\hline $38000-47999$ & 1031 & 16.2 & 1019 & 17.0 & 12 & 3.1 & \\
\hline 48000-62999 & 2433 & 38.1 & 2245 & 37.4 & 188 & 48.1 & \\
\hline$>63000$ & 2570 & 40.1 & 2384 & 39.7 & 186 & 47.6 & \\
\hline Total & 6395 & 100.0 & 6004 & 100.0 & 391 & 100.0 & \\
\hline
\end{tabular}

Abbreviations: NSCLC, non-small cell lung cancer; SBRT, stereotactic body radiotherapy; NOS, not otherwise specified; SEER: surveillance, epidemiology and end Result.

Table 2. Association with Cancer-Specific Mortality and Median Survival Time Among Patient Groups (SEER database, 2004-2015)

\begin{tabular}{lll}
\hline Group & Mortality, n/N (\%) & $\begin{array}{l}\text { Median survival time } \\
\text { (months) }\end{array}$ \\
\hline Overall & $29.5 \%(1886 / 6395)$ & 20 \\
SBRT & $29.0 \%(1739 / 6004)$ & 20 \\
Ablation & $37.6 \%(147 / 391)$ & 31 \\
\hline
\end{tabular}

Abbreviations: SEER, Surveillance, Epidemiology and End Results; SBRT, stereotactic body radiotherapy.

Table 3. Univariate Analysis Comparing Patient Survival (SBRT vs Ablation)

\begin{tabular}{lllll}
\hline & & \multicolumn{3}{l}{ Univariable Analysis } \\
\cline { 3 - 5 } Variable & Number & HR & $95 \%$ CI & $p$ \\
\hline NSCLC & 6395 & 0.931 & $0.821-1.055$ & 0.260 \\
SQCC & 2112 & 0.877 & $0.684-1.124$ & 0.299 \\
AD & 3113 & 0.919 & $0.768-1.099$ & 0.353 \\
\hline Abbreviations: & SBRT, stereotactic body radiotherapy; NSCLC, non-small cell lung \\
cancer; SQCC, Squamous cell carcinoma; AD, Adenocarcinoma; HR, hazard ratio; & \\
CI, confidence interval.
\end{tabular}

\section{Kaplan-Meier Analysis of Survival Curves between the SBRT and Ablation Groups}

No significant differences in survival curves were observed between the SBRT and ablation groups on Kaplan-Meier analysis, as shown in Figure 1. Among patients with stage IA NSCLC, survival $(\log$-rank $p>0.05)$ was similar in the ablation and SBRT groups (Figure 1A). Consistently, no significant differences in survival were observed between the two subtypes of NSCLC: SQCC (log-rank $p>0.05$ ) (Figure 1B) and AD (log-rank $p>0.05$ ) (Figure 1C). Our data demonstrated similar effects on survival of patients with stage IA SQCC and AD in the SBRT and ablation groups.

\section{Comparison of the Effects on Survival of Patients with Stage IA NSCLC between the SBRT and Ablation Groups}

No significant differences $(p=0.260)$ in the OS of patients with stage IA NSCLC were observed between the SBRT and ablation groups on univariate analysis (Table 3). Furthermore, no significant differences were observed in the OS of patients with stage IA SQCC $(p=0.299)$ and $\operatorname{AD}(p=0.353)$ between the two groups (Table 3). A Cox model with nine variables, including sex, age, differentiation grade, tumor size, histologic type, insurance status, year of diagnosis, geographic region, and treatment, showed an $\mathrm{HR}(95 \% \mathrm{CI})$ of $0.930(0.817-1.058, p=0.269)$ on comparing between the ablation and SBRT groups (Table 4). Then the following variables were excluded: insurance status, year of diagnosis, and geographic region (these covariates were not very close to the clinic), and a new Cox model was adjusted for age, sex, tumor size, differentiation grade, histologic type, and treatment.

Table 4. Multivariate Analysis Using a Cox Proportional Hazards Model in Patients with stage IA NSCLC

\begin{tabular}{|c|c|c|c|c|}
\hline \multirow[b]{2}{*}{ Variable } & \multicolumn{3}{|c|}{ Multivariable Analysis } & \multirow[b]{2}{*}{$p$} \\
\hline & $\overline{\mathrm{HR}}$ & $95 \% \mathrm{C}$ & & \\
\hline & & & & \\
\hline$<45$ & Reference & & & \\
\hline$\geq 45,<55$ & 4.020 & 0.977 & -16.539 & 0.054 \\
\hline$\geq 55,<65$ & 4.091 & 1.016 & -16.466 & 0.047 \\
\hline$\geq 65,<75$ & 4.872 & 1.213 & -19.566 & 0.026 \\
\hline$\geq 75$ & 5.244 & 1.306 & -21.054 & 0.019 \\
\hline Sex & & & & $<0.001$ \\
\hline Female & Reference & & & \\
\hline Male & 1.288 & 1.201 & -1.380 & \\
\hline Tumor size, $\mathrm{cm}$ & & & & $<0.001$ \\
\hline$\leq 1$ & Reference & & & \\
\hline$>1, \leq 2$ & 1.110 & 0.938 & -1.313 & 0.224 \\
\hline$>2, \leq 3$ & 1.242 & 1.049 & -1.471 & 0.012 \\
\hline Unknown & 2.655 & 1.602 & -4.399 & $<0.001$ \\
\hline Differentiated grade & & & & 0.003 \\
\hline Grade I & Reference & & & \\
\hline Grade II & 1.306 & 1.114 & -1.532 & 0.001 \\
\hline Grade III & 1.320 & 1.129 & -1.542 & $<0.001$ \\
\hline Grade IV & 1.211 & 0.794 & -1.847 & 0.374 \\
\hline Unknown & 1.187 & 1.028 & -1.370 & 0.019 \\
\hline Histologic type & & & & $<0.001$ \\
\hline Squamous cell carcinoma & Reference & & & \\
\hline Adenocarcinoma & 0.821 & 0.757 & -0.891 & $<0.001$ \\
\hline Large cell carcinoma & 1.190 & 0.883 & -1.605 & 0.253 \\
\hline Other & 0.923 & 0.836 & -1.018 & 0.110 \\
\hline Insurance status & & & & 0.001 \\
\hline Medicaid & Reference & & & \\
\hline Uninsured & 0.893 & 0.501 & -1.592 & 0.701 \\
\hline Unknown & 0.871 & 0.735 & -1.031 & 0.109 \\
\hline Insured & 0.782 & 0.694 & -0.882 & $<0.001$ \\
\hline Year of diagnosis & & & & $<0.001$ \\
\hline 2004-2007 & Reference & & & \\
\hline $2008-2011$ & 0.818 & 0.722 & -0.926 & 0.002 \\
\hline 2012-2015 & 0.738 & 0.644 & -0.845 & $<0.001$ \\
\hline Geographic region & & & & 0.005 \\
\hline East & Reference & & & \\
\hline Northwest & 2.282 & 1.081 & -4.817 & 0.030 \\
\hline West & 0.896 & 0.830 & -0.967 & 0.005 \\
\hline North & 0.895 & 0.805 & -0.995 & 0.040 \\
\hline Southwest & 0.901 & 0.724 & -1.122 & 0.352 \\
\hline Treatment & & & & 0.269 \\
\hline SBRT & Reference & & & \\
\hline Ablation & 0.930 & 0.817 & -1.058 & \\
\hline
\end{tabular}

Notes: a Multivariate analysis for age, sex, tumor size, tumor location, differentiated grade, histologic type, insurance status, year of diagnosis, geographic region and treatment.

Abbreviations: NSCLC, non-small cell lung cancer; NOS, not otherwise specified; $\mathrm{HR}$, hazard ratio; CI, confidence interval; SBRT, stereotactic body radiotherapy. 
A

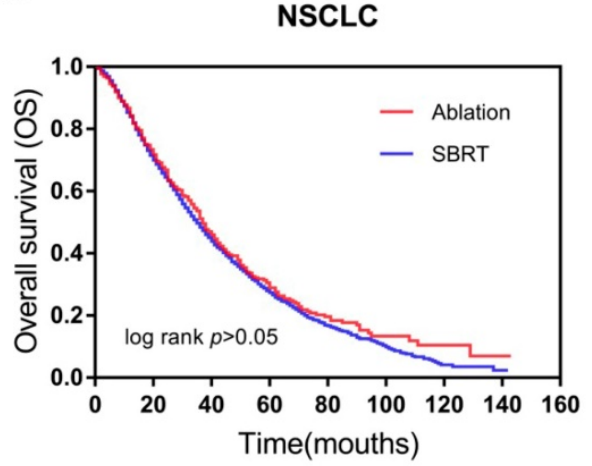

C

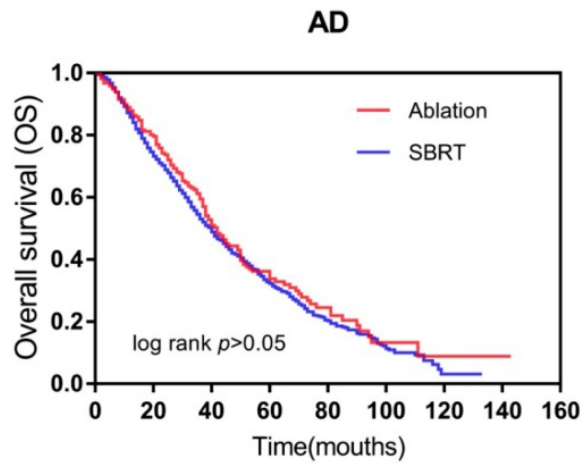

B

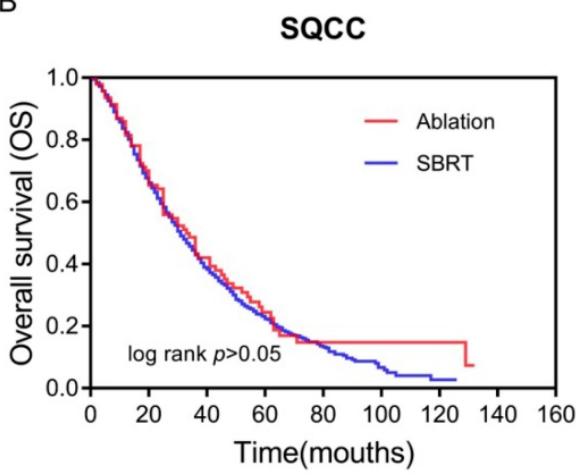

Figure 1. Survival curves based on Kaplan-Meier analysis for comparing between SBRT and ablation. (A) OS ( $>0.05$ ) of patients with early-stage NSCLC; (B) OS ( $>0.05$ ) of patients with early-stage SQCC; and (C) OS ( $>>0.05)$ of patients with early-stage AD. Abbreviations: OS, overall survival; NSCLC, non-small cell lung cancer; SBRT, stereotactic body radiotherapy; SQCC, squamous cell carcinoma; $A D$, adenocarcinoma.

Table 5. Univariable and Multivariable Analyses on OS in Patients with stage IA NSCLC

\begin{tabular}{|c|c|c|c|c|c|c|c|c|}
\hline \multirow{4}{*}{$\begin{array}{l}\text { Variable } \\
\text { Age, year } \\
<45\end{array}$} & \multicolumn{4}{|c|}{ Univariable analysis } & \multicolumn{4}{|c|}{ Multivariable analysis a } \\
\hline & \multirow[t]{2}{*}{ HR } & \multicolumn{2}{|c|}{$95 \% \mathrm{CI}$} & \multirow{2}{*}{$\begin{array}{c}p \\
<0.001\end{array}$} & \multirow[t]{2}{*}{ HR } & \multicolumn{2}{|c|}{$95 \% \mathrm{CI}$} & \multirow{2}{*}{$\begin{array}{r}p \\
0.001\end{array}$} \\
\hline & & & & & & & & \\
\hline & Reference & & & & Reference & & & \\
\hline$\geq 45,<55$ & 4.020 & 0.977 & -16.539 & 0.054 & 3.443 & 0.837 & -14.158 & 0.087 \\
\hline$\geq 55,<65$ & 4.091 & 1.016 & -16.466 & 0.047 & 3.364 & 0.836 & -13.533 & 0.088 \\
\hline$\geq 65,<75$ & 4.872 & 1.213 & -19.566 & 0.026 & 3.886 & 0.968 & -15.593 & 0.056 \\
\hline$\geq 75$ & 5.244 & 1.306 & -21.054 & 0.019 & 4.169 & 1.039 & -16.720 & 0.044 \\
\hline Sex & & & & $<0.001$ & & & & $<0.001$ \\
\hline Female & Reference & & & & Reference & & & \\
\hline Male & 1.288 & 1.201 & -1.380 & & 1.280 & 1.195 & -1.372 & \\
\hline Tumor size, $\mathrm{cm}$ & & & & $<0.001$ & & & & $<0.001$ \\
\hline$\leq 1$ & Reference & & & & Reference & & & \\
\hline$>1, \leq 2$ & 1.110 & 0.938 & -1.313 & 0.224 & 1.126 & 0.952 & -1.332 & 0.165 \\
\hline$>2, \leq 3$ & 1.242 & 1.049 & -1.471 & 0.012 & 1.283 & 1.084 & -1.519 & 0.004 \\
\hline Unknown & 2.655 & 1.602 & -4.399 & $<0.001$ & 3.035 & 1.835 & -5.018 & $<0.001$ \\
\hline Differentiated grade & & & & 0.003 & & & & 0.004 \\
\hline Grade I & Reference & & & & Reference & & & \\
\hline Grade II & 1.306 & 1.114 & -1.532 & 0.001 & 1.307 & 1.115 & -1.533 & 0.001 \\
\hline Grade III & 1.320 & 1.129 & -1.542 & $<0.001$ & 1.324 & 1.133 & -1.546 & $<0.001$ \\
\hline Grade IV & 1.211 & 0.794 & -1.847 & 0.374 & 1.311 & 0.860 & -1.997 & 0.208 \\
\hline Unknown & 1.187 & 1.028 & -1.370 & 0.019 & 1.202 & 1.042 & -1.387 & 0.012 \\
\hline Histologic type & & & & $<0.001$ & & & & $<0.001$ \\
\hline Squamous cell carcinoma & Reference & & & & Reference & & & \\
\hline Adenocarcinoma & 0.821 & 0.757 & -0.891 & $<0.001$ & 0.810 & 0.747 & -0.879 & $<0.001$ \\
\hline Large cell carcinoma & 1.190 & 0.883 & -1.605 & 0.253 & 1.256 & 0.931 & -1.694 & 0.135 \\
\hline Other & 0.923 & 0.836 & -1.018 & 0.110 & 0.958 & 0.869 & -1.056 & 0.384 \\
\hline Treatment & & & & 0.269 & & & & 0.680 \\
\hline SBRT & Reference & & & & Reference & & & \\
\hline Ablation & 0.930 & 0.817 & -1.058 & & 0.974 & 0.858 & -1.105 & \\
\hline
\end{tabular}

Notes: a Multivariate analysis for age, sex, tumor size, differentiated grade, histologic type, treatment.

Abbreviations: OS, overall survival; NSCLC, non-small cell lung cancer; HR, hazard ratio; CI, confidence interval; SBRT, stereotactic body radiotherapy.

In this model, the $\mathrm{HR}(95 \% \mathrm{Cl})$ was $0.974(0.858-$ $1.105, \mathrm{p}=0.680)$ on comparing between the ablation and SBRT groups (Table 5). These results indicated that no significant difference was observed between 
the effect of SBRT and ablation on the OS of patients with stage IA NSCLC.

\section{Discussion}

As some elderly patients with cardiopulmonary insufficiency or other comorbidities are not eligible for surgical treatment, non-invasive options, such as SBRT and ablation, have played an increasingly important role in the treatment of NSCLC 22,13 . Currently, no large-scale clinical trials have compared the therapeutic effect between ablation and SBRT and no independent cohorts which can be downloaded from publicly available databases to validate our main findings and conclusions, primarily owing to the novelty and limitations associated with the practical application of ablation treatment. Recently, Johannes Uhlig 11 conducted a retrospective study and reported that the estimated 1-, 3-, and 5-year OS rates of patients treated with ablation were comparable to those of patients treated with SBRT (1-year, $85.4 \%$ vs. $86.3 \%, p=0.76$; 3 -year, $47.8 \%$ vs. $45.9 \%, p=0.32$; 5 -year, $24.6 \%$ vs. $26.1 \%, p=0.81$ ). These results were similar to our findings. According to our study, no significant survival difference was seen on analyzing a large SEER dataset, which contained the information of patients diagnosed with stage IA NSCLC during 2005-2014. Our results provide a curative reference on the non-inferior survival benefits achieved with ablation as primary treatment for stage IA NSCLC.

At present, it is widely accepted that SBRT is the optimal curative approach for medically inoperable patients ${ }^{14}$. SBRT can reach occult regional and deep structures that are difficult to explore via surgery, resulting in prolonged survival. However, SBRT has a drawback; SBRT is associated with poor control of local pulmonary lesions or multiple metastatic disease, increasing the risk of cancer-specific death. Pneumonitis, dyspnea, and chest pain were most commonly reported adverse events associated with SBRT ${ }^{15}$, usually occurring approximately $4-12$ weeks after treatment, in a systematic review ${ }^{16,17}$. The incidence of toxicities induced by SBRT was higher in patients with central lung cancer (close to the airway) than in those with peripheral lung cancer ${ }^{18,19}$. In addition, patients with advanced age or multiple comorbidities tend to forego definitive treatment; this is one of the predominant reasons why the systemic adverse reactions of SBRT commonly appear gradually over long-term treatment. and would not become new detective reflection factors within 30 days of readmission to hospital ${ }^{18}$. Relatively, complications of ablation usually occur on the same day or within a few days of treatment; of these adverse events, self-limiting pneumothorax is the most common ${ }^{10,20}$. The majority of patients can experience relief after symptomatic treatment, and only a small proportion of patients $(10 \%-30 \%)$ need to undergo chest tube placement ${ }^{20,21}$. Other rare complications of ablation include pulmonary hemorrhage ${ }^{22,23}$, air embolism ${ }^{24,25}$, pleural effusion ${ }^{26}$, bronchopleural fistula formation ${ }^{27}$, bronchospasm ${ }^{10}$, and sometimes even death ${ }^{7}$. Considering the similarity in survival rates, fewer complications and better quality of life may be the main factors influencing the choice between SBRT and ablation for inoperable patients with stage IA NSCLC. This will be a direction for future research.

Although the SEER database provides a significant data-collecting platform for addressing this urgent issue, this investigation has some limitations. Although we conducted accurate matching of cohorts, this study was retrospective in nature; thus, the factors not included in the matching process may be responsible for the observed differences in outcome. In addition, OS was analyzed without any adjustment for radiation dose, toxicities, pulmonary function, cause of death, and local progression-free survival. Furthermore, the SEER database does not provide details regarding repetitive ablation treatments and feasible approaches, such as surgical, percutaneous, and bronchoscopic ablation. Therefore, further research is needed on this topic.

Due to its retrospective design, our study has some limitations. For example, the lack of original datum from our own studies as well as validation for main findings and conclusion. Nevertheless, with the inclusion of 15 variables and nearly 6400 patients in our cohort, the present study represents a well-balanced analysis of Ablation or SBRT treatment methods. Thus, in the absence of data from prospective trials, our findings can provide information that is useful for the management in inoperable patients with stage IA NSCLC.

\section{Conclusion}

According to the results of our study, no significant difference was observed in survival between inoperable patients with stage IA NSCLC who were treated with SBRT and ablation. Therefore, the quality of life after SBRT or ablation may be the main consideration for choosing the treatment method.

\section{Acknowledgments}

We would like to thank all the staff of the National Cancer Institute for their efforts in the SEER program. 


\section{Author Contributions}

Conception and design: L.L., S.S.X., and G.S.L. Acquisition, statistical analysis or interpretation of the data: all authors. Drafting of the manuscript: M.M.Z. F.Y.S. A.M.P. and G.F.Z. All authors reviewed and approved the final version of the manuscript.

\section{Funding}

We would like to thank all the staff of the National Cancer Institute for their efforts in the SEER program. This work was supported by the National Natural Science Foundation of China ([NSFC] no. 81802262), Shanghai Tenth Hospital's improvement plan for NSFC (no. 04.03.17.032, 04.01.18. 048), the Fundamental Research Funds for the Central Universities (no. 22120180584) and Shanghai Chongming district "sustainable development science and technology" (no. CKY2019-9).

\section{Ethical approval}

All procedures performed in this study involving human participants are in accordance with the ethical standards of the institutional and/or national research committee and with the 1964 Declaration of Helsinki and its later amendments or comparable ethical standards. For this type of study, formal consent is waived.

\section{Competing Interests}

The authors have declared that no competing interest exists.

\section{References}

1. Siegel RL, Miller KD, Jemal A, et al. Cancer statistics,2018. CA Cancer J Clin. 2018;68: 7-30

2. Oser MG, Niederst MJ, Sequist LV, et al. Transformation from non-small-cell lung cancer to small-cell lung cancer: molecular drivers and cells of origin. The Lancet(Oncology). 2015;16: e165-172.

3. Scott WJ, Howington J, Feigenberg S, et al. Treatment of non-small cell lung cancer stage I and stage II: ACCP evidence-based clinical practice guidelines (2nd edition). Chest. 2007; 132:234-242.

4. Menoux I, Antoni D, Truntzer P, et al. Stereotactic body radiation therapy for stage I non-small cell lung carcinomas: Moderate hypofractionation optimizes outcome. Lung cancer (Amsterdam, Netherlands). 2018; 126: 201-207.

5. El-Sherif A, Gooding WE, Santos R, et al. Outcomes of sublobar resection versus lobectomy for stage I non-small cell lung cancer: a 13-year analysis. The Annals of thoracic surgery. 2006; 82: 408-415; discussion 415-406.

6. Suh RD, Wallace AB, Sheehan RE, et al. Unresectable pulmonary malignancies: CT-guided percutaneous radiofrequency ablation--preliminary results. Radiology 2003; 229: 821-829.

7. Simon CJ, Dupuy DE, DiPetrillo TA, et al. Pulmonary radiofrequency ablation: long-term safety and efficacy in 153 patients. Radiology.2007; 243:268-275.

8. Verma V, Simone CB 2nd, Allen PK, et al. Multi-Institutional Experience of Stereotactic Ablative Radiation Therapy for Stage I Small Cell Lung Cancer. International journal of radiation oncology, biology, physics. 2017; 97: 362-371.

9. de Baere T, Farouil G, Deschamps F, et al. Lung cancer ablation: what is the evidence? Seminars in interventional radiology. 2013; 30: 151-156.

10. Dupuy DE. Image-guided thermal ablation of lung malignancies. Radiology. 2011; 260: 633-655

11. Uhlig J, Ludwig JM, Goldberg SB, et al. Survival Rates after Thermal Ablation versus Stereotactic Radiation Therapy for Stage 1 Non-Small Cell Lung Cancer: A National Cancer Database Study. Radiology. 2018; 289: 862-870.

12. Postmus PE, Kerr KM, Qudkerk M, et al. Early and locally advanced non-small-cell lung cancer (NSCLC): ESMO Clinical Practice Guidelines for diagnosis, treatment and follow-up. Annals of oncology : official journal of the European Society for Medical Oncology. 2017; 28(Suppl 4): iv1-iv21.
13. Lim E, Baldwin D, Beckles M, et al. Guidelines on the radical management of patients with lung cancer. Thorax. 2010; 65(Suppl 3), iii1-27.

14. Timmerman RD, Paulus R, Pass H, et al. Stereotactic Body Radiation Therapy for Operable Early-Stage Lung Cancer: Findings From the NRG Oncology RTOG 0618 Trial. JAMA oncology. 2018; 4:1263-1266.

15. Murray P, Franks K, Hanna GG, et al. A systematic review of outcomes following stereotactic ablative radiotherapy in the treatment of early-stage primary lung cancer. The British journal of radiology. 2017; 90:1071.

16. Davis SD, Yankelevitz DF, Henschke CI, et al. Radiation effects on the lung: clinical features, pathology, and imaging findings. AJR. American journal of roentgenology. 1992; 159: 1157-1164.

17. Libshitz HI, DuBrow RA, Loyer EM, et al. Radiation change in normal organs: an overview of body imaging. European radiology 1996; 6: 786-795.

18. Timmerman R, McGarry R, Yiannoutsos $C$, et al. Excessive toxicity when treating central tumors in a phase II study of stereotactic body radiation therapy for medically inoperable early-stage lung cancer. Journal of clinical oncology : official journal of the American Society of Clinical Oncology. 2006; 24: 4833-4839.

19. Chang JY, LiQQ, Xu QY, et al. Stereotactic ablative radiation therapy for centrally located early stage or isolated parenchymal recurrences of non-small cell lung cancer: how to fly in a "no fly zone". International journal of radiation oncology, biology, physics. 2014; 88: 1120-1128.

20. Hiraki T, Tajiri N, Mimura H, et al. Pneumothorax, pleural effusion, and chest tube placement after radiofrequency ablation of lung tumors: incidence and risk factors. Radiology. 2006; 241: 275-283.

21. Wolf FJ, Grand DJ, Machan JT, et al. Microwave ablation of lung malignancies: effectiveness, CT findings, and safety in 50 patients. Radiology. 2008; 247:871-879.

22. Wang H, Littrup PJ, Duan $Y$, et al. Thoracic masses treated with percutaneous cryotherapy: initial experience with more than 200 procedures. Radiology. 2005; 235: 289-298.

23. Zhang X, Tian J, Zhao L, et al. CT-guided conformal cryoablation for peripheral NSCLC: initial experience. European journal of radiology. 2012. 81: 3354-3362.

24. Ghaye B, Bruyere PJ, Dondelinger RF, et al. Nonfatal systemic air embolism during percutaneous radiofrequency ablation of a pulmonary metastasis. AJR. American journal of roentgenology. 2006; 187: W327-328.

25. Okuma T, Matsuoka T, Tutumi S, et al. Air embolism during needle placement for CT-guided radiofrequency ablation of an unresectable metastatic lung lesion. Journal of vascular and interventional radiology : JVIR. 2007; 18: 1592-1594.

26. Ni X, Han JQ, Ye X, et al. Percutaneous CT-guided microwave ablation as maintenance after first-line treatment for patients with advanced NSCLC. OncoTargets and therapy. 2015; 8: 3227-3235.

27. Kashima M, Yamakado K, Takaki H, et al. Complications after 1000 lung radiofrequency ablation sessions in 420 patients: a single center's experiences. AJR. American journal of roentgenology. 2011; 197: W576-580. 